\title{
ANTIBODY FORMATION IN CASES OF LOBAR PNEUMONIA TREATED WITH SULFAPYRIDINE
}

\author{
By YALE KNEELAND, JR., AND BARBARA MULLIKEN \\ (From the Department of Medicine, College of Physicians and Surgeons, Columbia University \\ and the Presbyterian Hospital, New York City)
}

(Received for publication October 19, 1939)

For many years it has been known $(1,2,3,4)$ that at the time of the crisis in lobar pneumonia, or immediately thereafter, an excess of typespecific antibody can be demonstrated in the blood serum of the patient. While this phenomenon is not absolutely invariable, most observers have agreed that it occurs in the great majority of instances. Conversely, in cases going on to a fatal termination, where crisis does not occur, no type-specific antibody can be demonstrated in the patient's serum during the course of the disease. These facts have led to the belief that spontaneous recovery in lobar pneumonia is intimately related to the patient's capacity for producing type-specific antibody in such amount as to react with all the available antigen in the body and actually to appear in excess in the blood serum. Moreover, in recent years the phenomenon has been used as a quantitative guide to serum therapy, administration of therapeutic serum being continued until an excess of antibody could be demonstrated in the patient's serum.

Since the introduction of sulfanilamide and related compounds in the treatment of infections, there has arisen intense speculation as to their mode of action. In view of the fact that these drugs, while definitely bacteriostatic, are not bactericidal, it is obvious that the ordinary defenses of the body must play an essential rôle in the successful operation of the drug, and evidence has been accumulated to show that phagocytosis of bacteria is more effective after they have been exposed to the action of sulfanilamide. In addition, the rôle of humeral antibodies has been studied experimentally, and it is the conclusion of a number of investigators that the effectiveness of these drugs is considerably enhanced if they act in the presence of immune serum.

In the case of human infections treated with sulfanilamide, an appraisal of the importance of active or passive immunity has not yet been made, and as this is a subject of some practical significance, it was considered worth while to investigate it further. The opportunity to do so was afforded by the introduction of sulfapyridine. Since this drug is an effective therapeutic agent against all types of pneumococcus, it was possible to study the immune reaction in human lobar pneumonia, a disease in which the development of active immunity was known to be of critical importance. Therefore, beginning in February 1939 each case of lobar pneumonia treated with sulfapyridine at the Presbyterian Hospital was investigated for the appearance of type-specific antibody.

Of the principal immune bodies which have been investigated in connection with lobar pneumonia, i.e. protective substances, agglutinins, and precipitins, we elected to study the latter. The precipitin reaction with specific soluble substance of pneumococcus has been the subject of extensive investigation by Heidelberger and his coworkers. That the type-specific precipitin and the agglutinin are the same antibody now seems to have been definitely proven (5). Moreover, an exceedingly close correlation has been shown to exist (6) between this antibody and the mouse protecting power of immune serum. As Heidelberger and Kendall ( 7 ) have stated, "while other reactions are more delicate, the precipitin test is among the most specific and least subject to errors and technical difficulties." The appearance of precipitins in the blood serum of thirteen patients recovering from lobar pneumonia, eight of whom had received serum therapy, was found by Tillett and Francis (8) to coincide with the appearance of agglutinins. For these reasons the precipitin test with type-specific polysaccharide was used in this study, according to the same technique which has been used in this clinic as a routine method of determining the adequacy of serum therapy. 


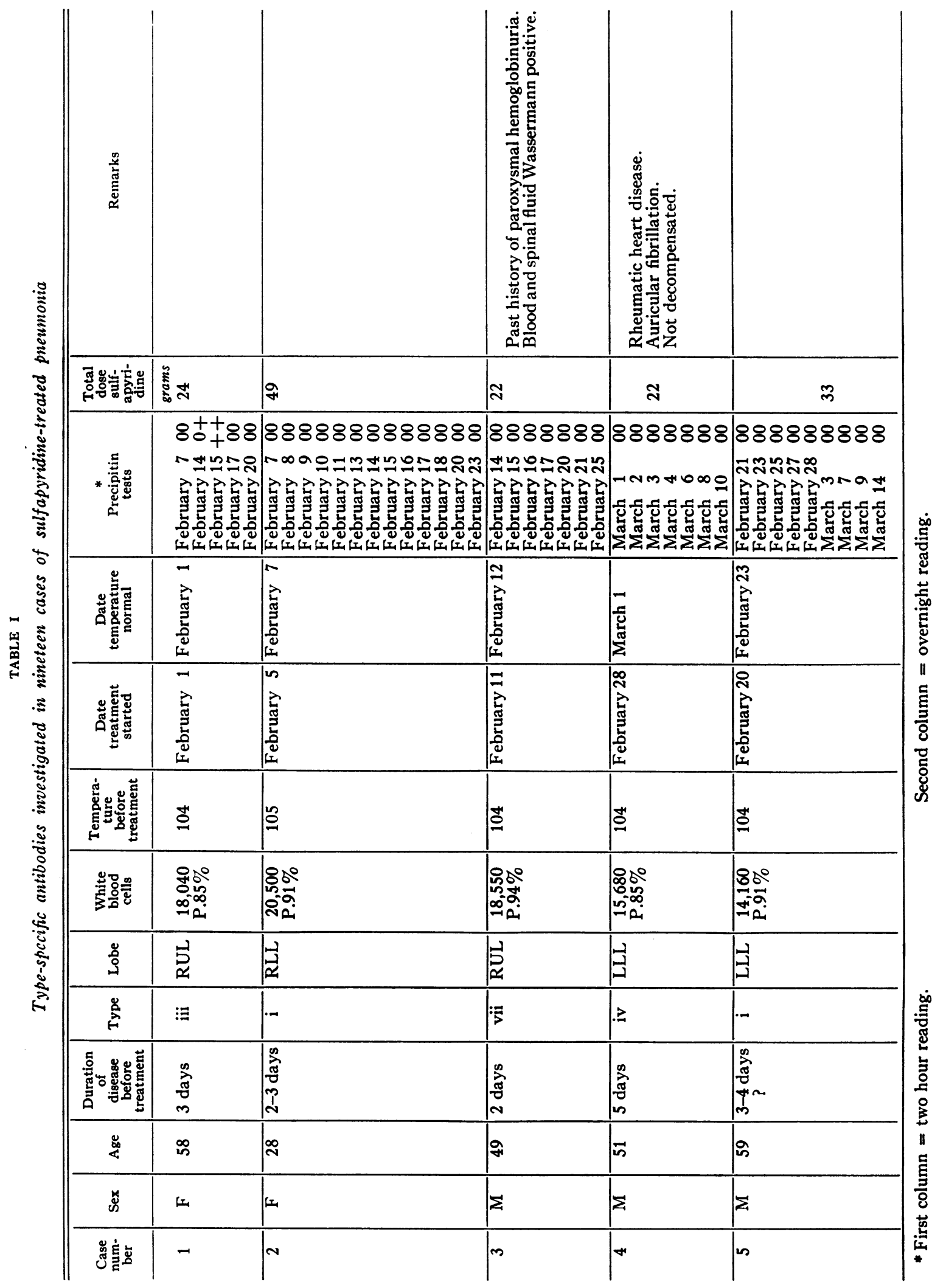




\begin{tabular}{|c|c|c|c|c|c|c|}
\hline 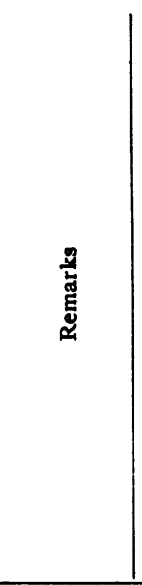 & & 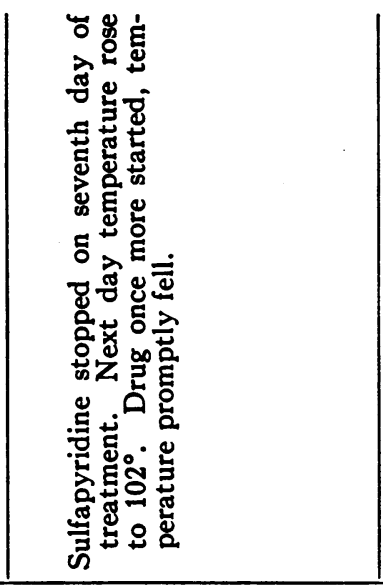 & & & 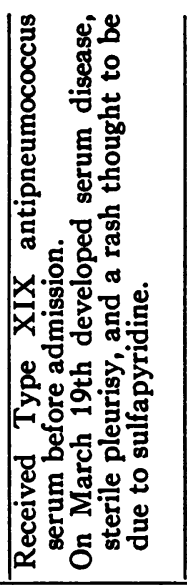 & \\
\hline 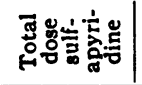 & ह్ & $\nexists ึ$ & ల్ల & 요 & 虫 & జ్లై \\
\hline 鸹总 & 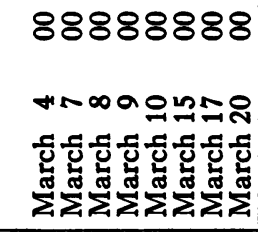 & 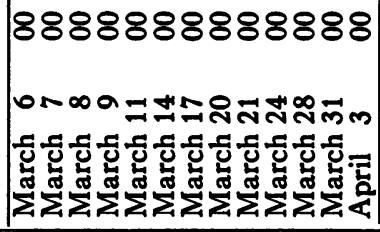 & 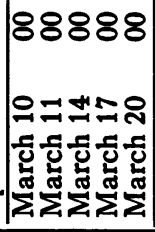 & 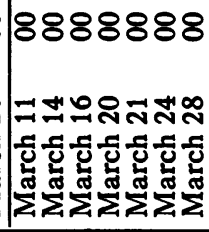 & 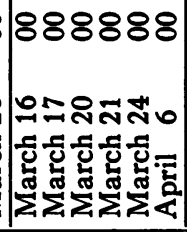 & 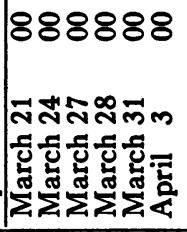 \\
\hline 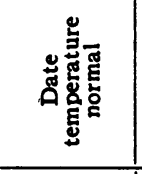 & $\begin{array}{l}n \\
\text { nj } \\
\sum^{5} \\
\end{array}$ & s & 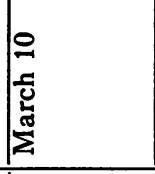 & $\begin{array}{l}\Xi \\
\overline{0} \\
0 \\
\vdots \\
\Sigma\end{array}$ & 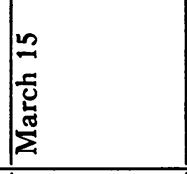 & 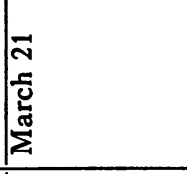 \\
\hline 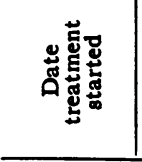 & 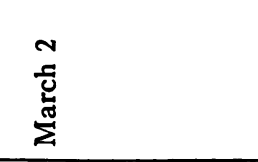 & 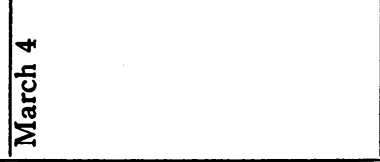 & 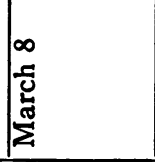 & 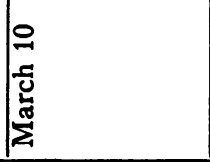 & 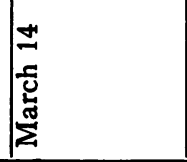 & 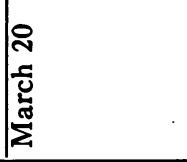 \\
\hline 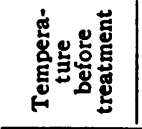 & 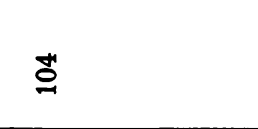 & 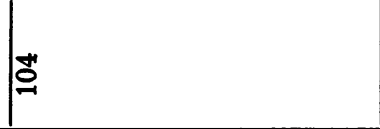 & 苑 & 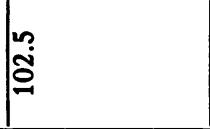 & $\stackrel{2}{2}$ & D্ \\
\hline 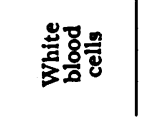 & 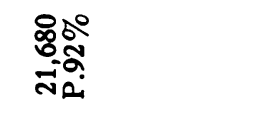 & 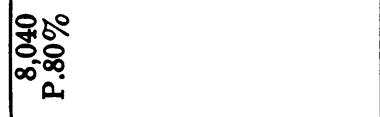 & 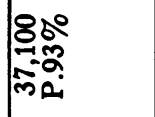 & 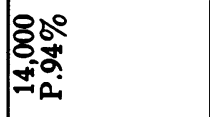 & 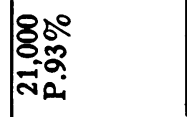 & 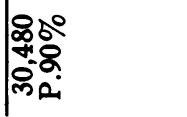 \\
\hline$\stackrel{2}{3}$ & 宫 & B & 幽 & 占 & बـ & 今 \\
\hline$\stackrel{\leftrightarrow}{\mathrm{g}}$ & $\vec{x}$ & $: \equiv$ & - & $: \equiv$ & $>$ & $:=$ \\
\hline 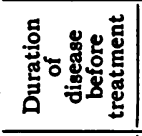 & $\begin{array}{l}\frac{n}{2} \\
\frac{\pi}{0} \\
m \\
\end{array}$ & $\begin{array}{l}\infty \\
\vdots \\
0 \\
0 \\
m \\
m\end{array}$ & \begin{tabular}{|l}
0 \\
$\vdots$ \\
0 \\
0 \\
0 \\
0
\end{tabular} & $\begin{array}{l}\infty \\
2 \\
0 \\
0 \\
0\end{array}$ & \begin{tabular}{l}
2 \\
\multirow{2}{0}{} \\
0 \\
0
\end{tabular} & 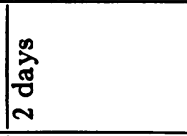 \\
\hline 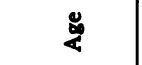 & $\ddot{m}$ & 8 & $\tilde{m}$ & pro & নิ & in \\
\hline$y$ & 15 & $\Sigma$ & $\Sigma$ & $\Sigma$ & Ir & $\Sigma$ \\
\hline 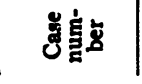 & 0 & N & $\infty$ & $a$ & 응 & $\Rightarrow$ \\
\hline
\end{tabular}




\begin{tabular}{|c|c|c|c|c|c|c|c|c|}
\hline • & & & & 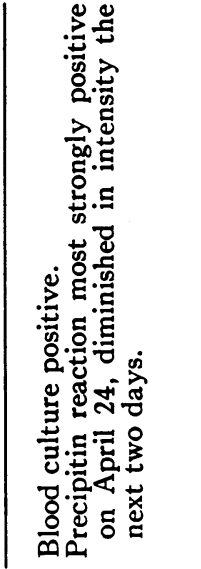 & & 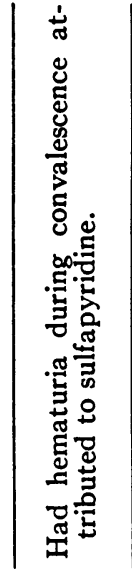 & 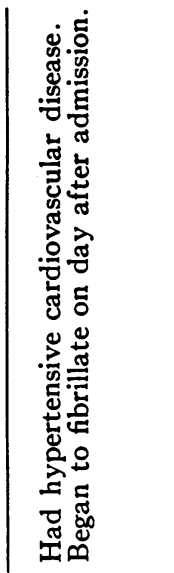 & \\
\hline 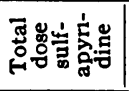 & ล & $\tilde{\text { กี }}$ & o & กิ & ల్లు & $\tilde{\sim}$ & $\stackrel{n}{\infty}$ & \& \\
\hline * & 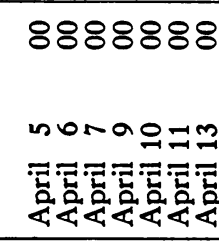 & 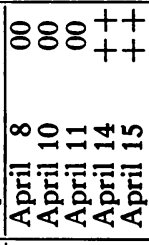 & 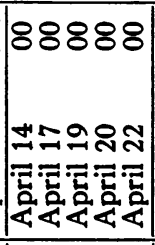 & 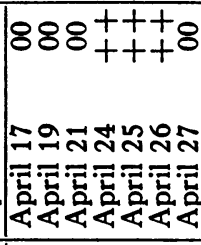 & 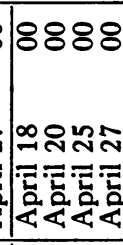 & 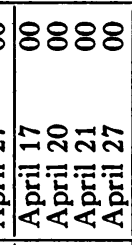 & 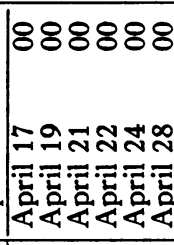 & 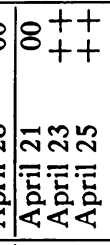 \\
\hline 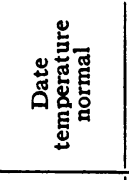 & $\begin{array}{l}n \\
\text { 茨 } \\
\end{array}$ & 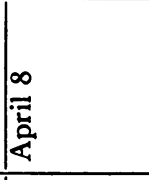 & 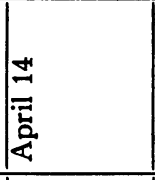 & 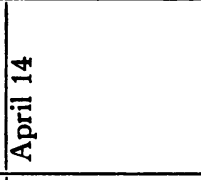 & 叒 & $\mid$\begin{tabular}{l}
0 \\
$\cdots$ \\
\hdashline \\
$\frac{2}{2}$
\end{tabular} & 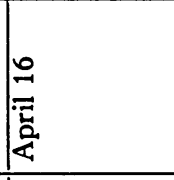 & 告 \\
\hline 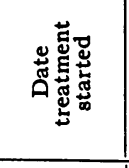 & $\stackrel{m}{\vec{Z}}$ & 焉 & 怼 & 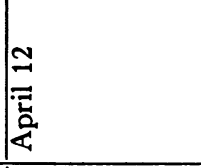 & 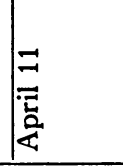 & 告 & 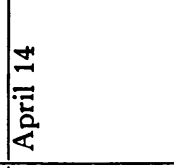 & 焉 \\
\hline 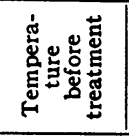 & ธิ & 总 & م & مَ & 芯 & חִ & 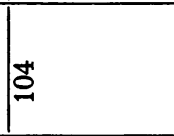 & 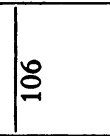 \\
\hline 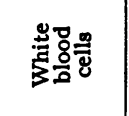 & 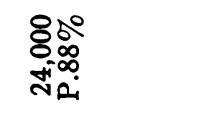 & 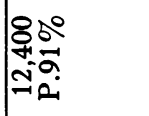 & 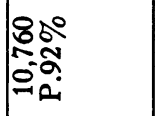 & 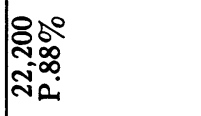 & 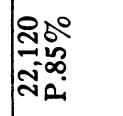 & 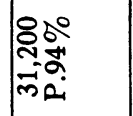 & 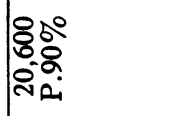 & $\mid$ \\
\hline$\stackrel{8}{9}$ & 马 & 三 & |컴 & 峉 & | & 侊 & 㝳 & 岁 \\
\hline 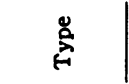 & 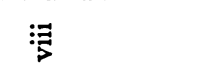 & 5 & $: \equiv$ & - & $: \overrightarrow{7}$ & ::三 & $:: \nexists$ & - \\
\hline 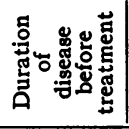 & 莞 & 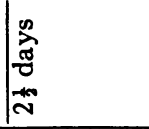 & 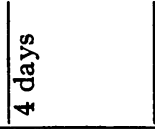 & $\begin{array}{l}\infty \\
2 \\
\frac{\pi}{0} \\
m \\
m\end{array}$ & 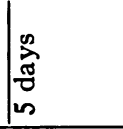 & 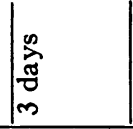 & 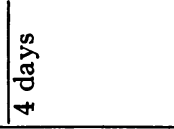 & 瓷 \\
\hline 通 & $\vec{m}$ & 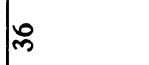 & aे & in & is & $\infty$ & $\approx$ & $\approx$ \\
\hline 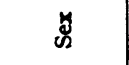 & $\Sigma$ & $\Sigma$ & $\Sigma$ & $\Sigma$ & 14 & $\Sigma$ & $\Sigma$ & Lr \\
\hline 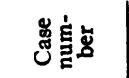 & $\cong$ & $m$ & $\boxplus$ & 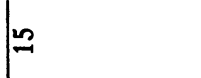 & 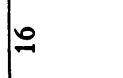 & $\approx$ & $\cong$ & $a$ \\
\hline
\end{tabular}




\section{MATERIALS AND METHODS}

Serum was obtained from each case of lobar pneumonia as often as was practicable during the entire hospital stay. Detection of antibody was made by means of the precipitin reaction with type-specific polysaccharide according to the technique of Dr. Michael Heidelberger. To one cc. of serum was added one drop of a $1: 50,000$ dilution of specific polysaccharide 1 derived from the same type of pneumococcus as that isolated from the patient's sputum. At the end of an hour, if the test were negative, three or four more drops were added. The tests were read after two hours at room temperature, and again after a night at ice box temperature. (Except in one instance, all the positive reactions were clear-cut at the end of two hours.) As a control, another tube was set up with a few drops of normal salt solution. In addition, all human serums were set up with type-specific antiserum to detect the presence of circulating polysaccharide. (This reaction was only found to be positive in one case; as therapeutic serum was promptly administered, this case is not included below.) The results of the tests for type-specific antibody are given in Table $\mathrm{I}$.

\section{RESULTS}

Nineteen cases of lobar pneumonia treated with sulfapyridine were investigated for the appearance of type-specific antibodies. Altogether one hundred and twenty-seven samples of serum were tested by means of the precipitin reaction with specific polysaccharide. Of the nineteen cases, only four were shown to have an excess of type-specific antibody in the blood, and in these four the antibody did not appear at the time of, or immediately after, the "crisis" induced by sulfapyridine. As nearly as can be determined from the data, antibodies in these four cases were first detectable after about a week of normal temperature. A study of the fever curves in the whole series indicates that the temperature fell to normal following sulfapyridine therapy within twenty-four hours in nine cases, within forty-eight hours in six, and within seventy-two in four cases. The fall to normal in those cases developing antibodies occurred in twenty-four hours in two cases, and in forty-eight and seventy-two hours in the other two respectively-a result exactly comparable to the rest of the series. Moreover, the duration of disease before sulfapyridine therapy was begun was no greater in the cases which developed antibodies than in those which did not.

1 The specific polysaccharides used in these tests were kindly supplied by Dr. Michael Heidelberger, to whom thanks are due, not only for them, but for invaluable advice.
Seven other cases were studied but not included in the series listed above, because each received, in addition to the sulfapyridine, a certain amount of therapeutic antipneumococcus serum. Two of these were due to Type I pneumococcus and both promptly showed an excess of antibody after serum therapy; five were due to Type III, and, of these, three promptly showed an excess of antibody.

\section{DISCUSSION}

These observations indicate that in nearly eighty per cent of a small series of cases of lobar pneumonia treated with sulfapyridine recovery took place without the appearance of an excess of type-specific antibodies. In view of the fact that the production of an excess of antibodies has hitherto been regarded as an essential part of the mechanism of spontaneous recovery from pneumonia, it must be concluded that sulfapyridine has supplanted, at least to some degree, this part of the immune mechanism. There is no evidence, of course, that antibody production ceases to occur in the presence of sulfapyridine; on the contrary, it is highly probable that it occurs, at least to some extent. Such, indeed, is suggested by the fact that in the cases where antibody appeared in excess, it did so later than has been observed in untreated cases, implying that production has been going on at a slower rate, probably because the stimulus to antibody formation is lessened through the action of the drug on the invading organism. Moreover, this abnormally low rate of antibody formation may explain the well-known clinical finding that if treatment with sulfapyridine is stopped too soon, even if the patient has had no fever for several days, a recrudescence of the pneumonia may take place. Finally, these observations do not settle the question as to whether therapeutic antiserum should or should not be given along with the drug; they merely indicate that demonstrable antibodies are not essential to recovery.

\section{SUMMARY AND CONCLUSIONS}

1. Nineteen cases of lobar pneumonia treated with sulfapyridine were studied for the appearance of type-specific antibodies in the blood serum, as judged by the precipitin reaction with specific polysaccharide. 
2. In only four instances was an excess of antibodies demonstrated, and in these cases antibodies were not noted until after the patient's temperature had been normal about a week.

3. The significance of these findings is discussed.

\section{BIBLIOGRAPHY}

1. Klemperer, G., and Klemperer, F., Versuche uber Immunisirung und Heilung bei der Pneumokokkeninfection. Berl. Klin. Wchnschr., 1891, 28, 869.

2. Dochez, A. R., The presence of protective substances in human serum during lobar pneumonia. J. Exper. Med., 1912, 16, 665.

3. Chickering, H. T., Agglutination phenomena in lobar pneumonia. J. Exper. Med., 1914, 20, 599.

4. Blake, F. G., Antigen-antibody balance in lobar pneumonia. Arch. Int. Med., 1918, 21, 779.

5. (a) Francis, T., Jr., The identity of the mechanisms of type-specific agglutinin and precipitin reactions with pneumococcus. J. Exper. Med., 1932, 55, 55.

(b) Heidelberger, M., and Kabat, E. A., Chernical studies on bacterial agglutination. II. The identity of precipitin and agglutinin. J. Exper. Med., 1936, 63, 737.

6. (a) Heidelberger, M., Sia, R. H. P., and Kendall, F., Specific precipitation and mouse protection in Type I antipneumococcus sera. J. Exper. Med., 1930, $52,477$.

(b) Felton, L. D., The correlation of the protective value with the titers of other antibodies in Type I antipneumococcus serum. J. Immunol., 1931, 21, 341.

(c) Barnes, L. A., Clarke, C. M., and Wight, E. C., Comparisons of various methods for the routine titration of Types I and II antipneumococcus horse serums. J. Immunol. 1936, 30, 127.

7. Heidelberger, M., and Kendall, F. E., A quantitative study of the precipitin reaction between Type III pneumococcus polysaccharide and purified homologous antibody. J. Exper. Med., 1929, 50, 809.

8. Tillett, W. S., and Francis, T., Jr., Cutaneous reactions to the polysaccharides and proteins of pneumococcus in lobar pneumonia. J. Exper. Med., 1929, 50, 687. 